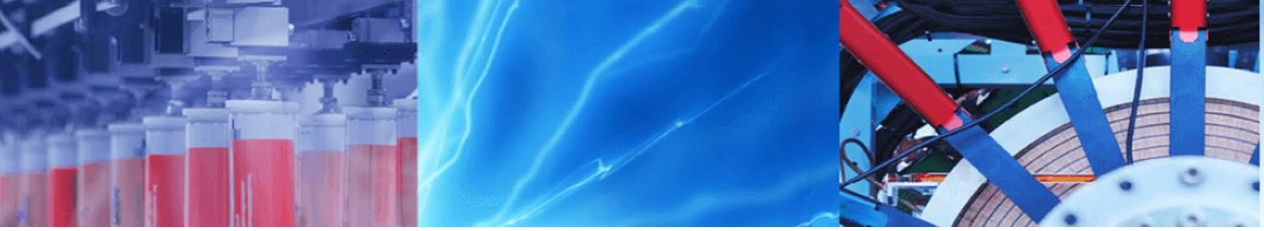

Research Article

\title{
A stoichiometric approach to find optimum amount of fly ash needed in cement concrete
}

\author{
Muhammad Raheel $^{1}$ [D $\cdot$ Fayyaz Rahman ${ }^{1} \cdot$ Qaisar $^{\text {Ali }^{1}}$
}

Received: 7 April 2020 / Accepted: 15 May 2020 / Published online: 20 May 2020

(c) Springer Nature Switzerland AG 2020

\begin{abstract}
This study aimed to find the optimum amount of fly ash that can be replaced with cement using a stoichiometric approach. For this purpose, the balanced chemical reactions between cement, water and fly ash were studied. This new proposed methodology uses information like chemical composition of cement, elemental composition and crystallinity in fly ash sample, and can easily find the optimum amount of fly ash that can replace cement. Considering the chemical composition analysis and percentage crystallinity in fly ash sample, the quantity of fly ash that can replace cement came out to be $30 \%$. To assess the performance of control group and partially replaced cement (PRC) samples, specimens were casted and different tests like compressive strength, split-tensile strength, density and sorption were conducted. The experimental results showed that PRC samples gained almost $95 \%$ compressive strength as that of control group at 90 days. The resistance to water intrusion as measured with sorption test showed that PRC samples had almost $50 \%$ less depth as compared to control group. The improvement in mechanical and durability properties of PRC samples supports the outcome of studied chemical reactions. The fly ash consumed the cement hydration product i.e. calcium hydroxide for producing binder gel; which enhanced the strength, lowered permeability and made the concrete denser. The development of compressive strength and density with time shows good agreement with an $R^{2}$ value of 0.96 .
\end{abstract}

Keywords Fly ash · Cement concrete · Compressive strength · Split-tensile strength · Sorption · Balanced chemical reactions

\section{Introduction}

Concrete is a widely used structural material due to its high strength, durability and readily available constituents. It has widespread uses ranging from building construction to canal and drainage linings [1], rigid pavements [2] and other precast applications [3]. The basic constituents of concrete include sand, coarse aggregates, cement and water. Cement is the binding material in concrete which needs water to unlock its cohesive and binding properties. The chemical reaction between cement and water is called hydration of cement which is accompanied with the release of heat and subsequent rise of $\mathrm{pH}$ of the solution.
As a result of chemical reaction, different compounds such as calcium-silicate hydrate (C-S-H) gel, calcium-aluminate hydrate $(\mathrm{C}-\mathrm{A}-\mathrm{H})$ gel and calcium hydroxide is formed. These different types of gels contribute towards strength of concrete [4]. However, the production of their parent material i.e. cement is accompanied with the emission of large amount of carbon dioxide. Global warming is already on peak with subsequent changes in climate patterns and melting of glaciers. Therefore, ideas are now shifted towards more sustainable construction practices $[5,6]$.

The incorporation of pozzolanic materials in concrete has been practiced from a long time. Different types of artificial pozzolanic materials used are fly ash, silica

Muhammad Raheel, mraheel14@gmail.com; raheel@uetpeshawar.edu.pk; Fayyaz Rahman, enginrfayyaz@gmail.com; Qaisar Ali, qasarali@uetpeshawar.edu.pk | 1 Department of Civil Engineering, University of Engineering and Technology Peshawar, Peshawar, Pakistan.

SN Applied Sciences (2020) 2:1100 | https://doi.org/10.1007/s42452-020-2913-y 
fume and furnace slag. The major compounds found in these materials are silica, alumina and iron oxide $[7,8]$. Silica fume contains the largest percentage of silicon dioxide. It has been shown that the reactivity of pozzolanic materials increases with increased surface area and smaller portion of crystalline matter [9]. When used in concrete, it improves its durability, minimizes shrinkage and enhance the strength of concrete. Fly ash is obtained when coal is burned in thermal power plants. The remaining residue of coal after burning is collected in a furnace $[10,11]$. Since, it is a waste material and, usually dumped in natural water bodies or landfill sites. Its use in concrete enhances its properties and also reduces cement consumption and environmental pollution [12].

It has been widely accepted and known that the incorporation of fly ash in concrete leads to higher strength development at later ages, reduced permeability, shrinkage and higher resistance to chloride ion penetration, thereby, indicating excellent durability properties [13]. However, the studies on fly ash concrete has been done using trials, and the percentage replacement which gave the optimal properties was concluded to be the optimum amount. For example, the study conducted by Duran [14] involved high volume replacement of cement with Class F fly ash (50\% and 70\%) and observed its influence on the strength and shrinkage property of concrete. It was obtained that fly ash samples developed higher compressive and split-tensile strength at later ages (beyond 28 days). The fly ash samples also showed $30 \%$ less shrinkage as compared to control group specimens. Similar trend was observed in the improvement of various properties such as strength and durability by [15], with $30 \%$ and $40 \%$ replacement of cement with fly ash (Class F). In these studies, the mechanical properties of concrete enhanced with time but it still lagged behind the control group specimens. The use of fly ash in engineered cementitious composites (ECC) along with steel fibers has also been studied by [16]. The aim was to reduce the amount of cement in ECC. For this purpose, different amounts of cement such as $40 \%, 60 \%, 80 \%$ and $100 \%$ were replaced with Class $\mathrm{F}$ fly ash. It was obtained that fly ash contributed towards strength development at later ages, thereby overcoming the reduction in strength due to low cement content. The effect of addition of fly ash on the fracture toughness of concrete has also been studied by various researchers $[17,18]$. It was obtained that concrete has normal fracture toughness characteristics up to $20 \%$ replacement of fly ash with cement. Increased amounts of fly ash replacement lower the fracture toughness of concrete specimens. It was also observed that the addition of fly ash affected the shape, width and trajectory of cracks in the specimens [19].
It is evident from previous literature that the addition of fly ash to concrete resulted in improved properties. However, it is also evident that fly ash was added as a partial replacement of cement by conducting trials i.e. by adding different percentages of fly ashes; and the percentage which gave better results was reported to be the optimum amount. In the previous literature, there is not a single method to find the optimum amount of fly ash directly without conducting trials. Therefore, there is a need to find a method which would directly give us the optimum amount of fly ash thus, eliminating the need for conducting trials.

The aim of this study is to find actual amount of fly ash needed to utilize all of the calcium hydroxide produced from cement hydration using balanced chemical reactions between cement, water and fly ash. For this purpose, the chemical reactions were studied and maximum amount of fly ash that could be added as a partial replacement to cement was determined. To compare their performance with control group samples and verify the products of these chemical reactions, different experimental tests such as compressive strength, splittensile strength and sorption were also carried-out.

\section{Properties of raw ingredients}

\subsection{Fine and coarse aggregate}

According to ACI Mix Design method [20], different properties of aggregates such as their specific gravities [21, 22], fineness modulus and gradation curve [23] must be known before carrying out a mix design trial. The specific gravity and water absorption results of both fine \& coarse aggregates are shown in Table 1 . The sieve analysis graph is shown in Fig. 1. The fineness modulus of sand came out to be 2.6 .

Table 1 Specific gravity and water absorption values of aggregates

\begin{tabular}{lll}
\hline Sample & Property & Value \\
\hline Coarse aggregate & Bulk specific gravity (oven dried) & 2.69 \\
& $\begin{array}{l}\text { Bulk specific gravity (saturated-surface } \\
\text { dry) }\end{array}$ & 2.71 \\
& Apparent specific gravity & \\
& Water absorption, \% & 2.75 \\
Fine aggregate & Specific gravity & 0.71 \\
& Water absorption, \% & 2.61 \\
& & 1.4 \\
\hline
\end{tabular}


Fig. 1 Particle size distribution analysis of fine and coarse aggregate

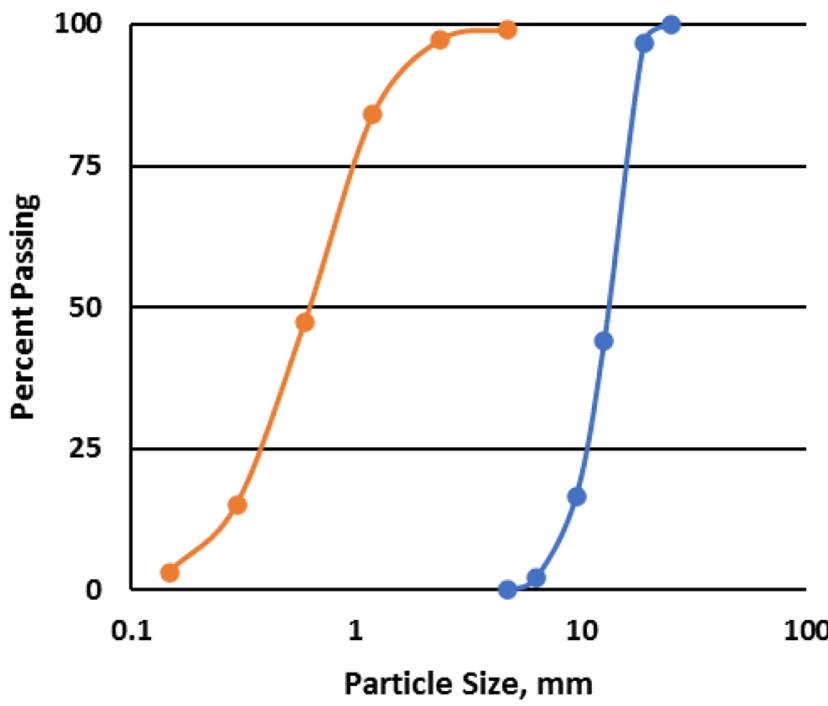

- Fine Aggregate
Table 2 XRF test result

\begin{tabular}{llllc}
\hline Fly ash & & & \multicolumn{2}{l}{ Ordinary portland cement } \\
\cline { 1 - 1 } \cline { 5 - 5 } Compound & Percentage & & Compound & Percentage \\
\hline $\mathrm{SiO}_{2}$ & 40.00 & & $\mathrm{SiO}_{2}$ & 21.00 \\
$\mathrm{Al}_{2} \mathrm{O}_{3}$ & 26.32 & & $\mathrm{Al}_{2} \mathrm{O}_{3}$ & 6.00 \\
$\mathrm{Fe}_{2} \mathrm{O}_{3}$ & 15.16 & & $\mathrm{Fe}_{2} \mathrm{O}_{3}$ & 2.58 \\
$\mathrm{CaO}$ & 7.83 & & $\mathrm{CaO}$ & 60.02 \\
$\mathrm{SO}_{3}$ & 6.14 & & $\mathrm{SO}_{3}$ & 9.30 \\
$\mathrm{TiO}_{2}$ & 2.55 & & $\mathrm{TiO}_{2}$ & 0.29 \\
$\mathrm{~K}_{2} \mathrm{O}$ & 1.41 & & $\mathrm{~K}_{2} \mathrm{O}$ & 0.81 \\
\hline
\end{tabular}

\subsection{X-ray fluorescence analysis of fly ash and cement}

ASTM C618 [24] classifies fly ash into Class N, F and C on the basis of its chemical composition and physical properties. The chemical composition of fly ash is studied with the help of X-ray fluorescence (XRF) and quantitative X-ray diffraction (XRD) analysis. The former test presents the oxidal composition whereas, the later shows the amount of crystalline and amorphous phase present in a given fly ash sample. Greater the crystalline content, lesser will be the reactivity of fly ash in concrete. The knowledge about the crystalline and amorphous phase is important as it will be used in the mix design calculations. The XRF test result is shown in Table 2.

Based on the XRF result, the fly ash sample can be categorized into class $\mathrm{F}$ as the amount of calcium oxide is less than $18 \%$ and the sum of silica, alumina and iron oxide is greater than $50 \%$. Similarly, quantitative amount of crystalline and amorphous content in the fly ash sample was obtained by quantitative $X R D$ analysis. Figure 2 shows the XRD analysis result. According to XRD test result, about $74.2 \%$ of the fly

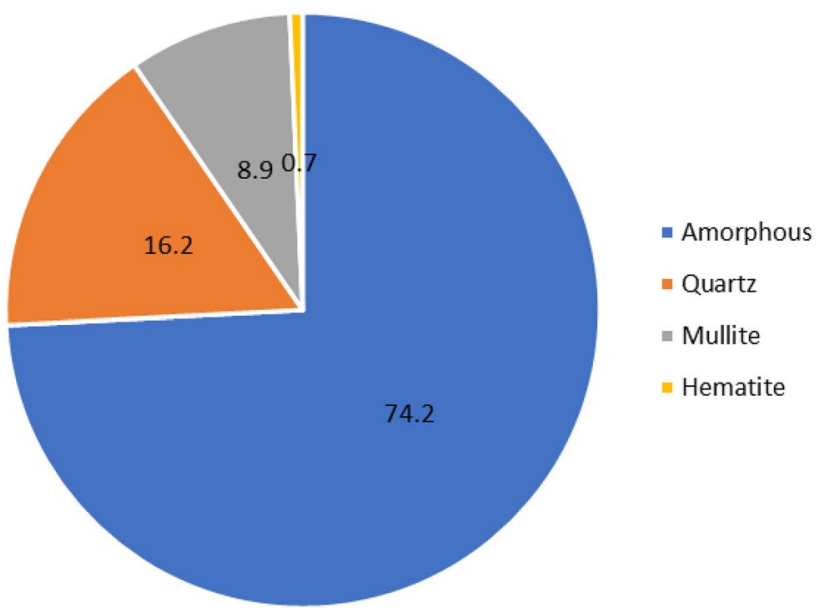

Fig. 2 Quantitative XRD analysis of fly ash

ash sample is amorphous, which means that the remaining amount (25.8\%) will not contribute towards any chemical reaction with ordinary Portland cement hydration products. This is very important result regarding stoichiometric calculations and the amount of fly ash actually needed to consume cement hydration products.

The amount of tricalcium-silicate, dicalcium-silicate, tricalcium-aluminate and tetra-calcium-alumino ferrite in cement sample was determined using Bogue's equation [25].

\section{Chemical reactions (cement hydration and fly ash)}

It is well known that upon cement hydration, calciumsilicate hydrate gel and calcium hydroxide are formed. The presence of calcium hydroxide maintains a high $\mathrm{pH}$ 
environment inside concrete and prevents corrosion of steel reinforcement (Reinforced cement concrete applications). However, a number of problems are also associated with it; such as leaching out with water making concrete structure porous and, its reaction with carbon dioxide to form calcium carbonate which leads towards expansion and disintegration of concrete [26]. Thus, the concrete structure loses its durability and its design life gets shortened.

It was shown from previous studies that fly ash was added to concrete using trials. In order to calculate the actual amount of fly ash needed for a particular mix design, it is imperative to know about the balanced chemical reactions that occur between cement, water and their products with fly ash.

Upon addition of water to ordinary portland cement, the following chemical reactions takes place:

$$
\begin{aligned}
& 2\left(3 \mathrm{CaO} \cdot \mathrm{SiO}_{2}\right)+7 \mathrm{H}_{2} \mathrm{O} \rightarrow 3 \mathrm{CaO} \cdot 2 \mathrm{SiO}_{2} \cdot 4 \mathrm{H}_{2} \mathrm{O}+3 \mathrm{Ca}(\mathrm{OH})_{2} \\
& 2\left(2 \mathrm{CaO} \cdot \mathrm{SiO}_{2}\right)+5 \mathrm{H}_{2} \mathrm{O} \rightarrow 3 \mathrm{CaO} \cdot 2 \mathrm{SiO}_{2} \cdot 4 \mathrm{H}_{2} \mathrm{O}+\mathrm{Ca}(\mathrm{OH})_{2} \\
& 3 \mathrm{CaO} \cdot \mathrm{Al}_{2} \mathrm{O}_{3}+6 \mathrm{H}_{2} \mathrm{O} \rightarrow 3 \mathrm{CaO} \cdot \mathrm{Al}_{2} \mathrm{O}_{3} \cdot 6 \mathrm{H}_{2} \mathrm{O} \\
& 4 \mathrm{CaO} \cdot \mathrm{Al}_{2} \mathrm{O}_{3} \cdot \mathrm{Fe}_{2} \mathrm{O}_{3}+7 \mathrm{H}_{2} \mathrm{O} \\
& \rightarrow 3 \mathrm{CaO} \cdot \mathrm{Al}_{2} \mathrm{O}_{3} \cdot 6 \mathrm{H}_{2} \mathrm{O}+\mathrm{CaO} \cdot \mathrm{Fe}_{2} \mathrm{O}_{3} \cdot \mathrm{H}_{2} \mathrm{O}
\end{aligned}
$$

It can be inferred from the above reactions that it is possible to calculate the amount of calcium hydroxide produced from a given amount of cement and water. For example, $2 \mathrm{~mol}$ of tricalcium silicate $(456 \mathrm{~g})$ reacts with $7 \mathrm{~mol}$ of water $(126 \mathrm{~g})$ to form $3 \mathrm{~mol}$ of C-S-H gel ( $342 \mathrm{~g}$ ) and calcium hydroxide ( $222 \mathrm{~g})$. Similarly, 2 mol of dicalcium silicate produces about $74 \mathrm{~g}$ calcium hydroxide. The remaining two constituents of cement do not produce any calcium hydroxide. The standard chemical reactions give us the amount of both reactant and product. To find the amount of product for some other quantity of reactant, one can simply use cross multiplication. Considering these standard chemical reactions and the chemical composition of cement, it was estimated that about $29 \%$ calcium hydroxide is produced by weight of cement.

To consume this amount of calcium hydroxide, the amount of fly ash comes out to be $63 \%$ of amount of calcium hydroxide determined from its standard chemical reactions with fly ash using the above stated calculation steps. The standard chemical reaction between fly ash and calcium hydroxide is given below:

$3\left(\mathrm{SiO}_{2}\right)+3\left(\mathrm{Ca}(\mathrm{OH})_{2}\right)+6 \mathrm{H}_{2} \mathrm{O} \rightarrow 3\left(\mathrm{CaO} \cdot \mathrm{SiO}_{2} \cdot 3 \mathrm{H}_{2} \mathrm{O}\right)$
$3 \mathrm{Al}_{2} \mathrm{O}_{3}+3 \mathrm{H}_{2} \mathrm{O}+3\left(\mathrm{Ca}(\mathrm{OH})_{2}\right) \rightarrow 3\left(\mathrm{CaO} \cdot \mathrm{Al}_{2} \mathrm{O}_{3} \cdot 6 \mathrm{H}_{2} \mathrm{O}\right)$

Silica and alumina are the two main components of fly ash leading to the development of calcium-silicate hydrate and calcium-aluminate hydrate gel. In our study sample, only 66 grams of silica and alumina is available for every 100 grams of fly ash used for reaction with hydration products.

During mix design of concrete, the amount of each ingredient is found per unit volume. The determination of amount of fly ash from balanced chemical reaction is a cyclic process unless and until the amount of cement and fly ash added equals the original amount of binder (cement) in control group concrete as shown in Fig. 3. Since, it was already established that crystalline portion of fly ash does not take part in chemical reaction, it was accommodated in mix design by replacing fine aggregate.

\section{Mix design}

The mix design of control group concrete was accomplished using $\mathrm{ACl}$ mix design method, shown in Table 3. The mix design was done for a zero-slump concrete using a water to cement ratio of 0.50 , without the addition of any admixture. Using the balanced chemical reactions and subsequent check as shown in workflow diagram, the mix design proportions of PRC concrete samples is also shown in Table 3. Figure 4 shows the mixing of concrete constituents and their subsequent casting in cylindrical molds. Ordinary tap water was used for both control group and PRC samples. All the specimens were demolded after $24 \mathrm{~h}$ and, wet cured under water at normal temperature until the desired testing age.

Based on the chemical composition of fly ash and stoichiometric equations, only $30 \%$ cement can be replaced with the study fly ash sample including crystalline portion ( $25 \%$ cement and $5 \%$ sand replacement). It is important to state again that cement was only replaced for amorphous content, crystalline portion being accommodated by replacing sand.

\section{Results and discussions}

The performance of control and PRC samples was compared by conducting different experimental tests such as compressive strength [27], split-tensile strength [28], sorption [29] and density of samples [27] as shown in Fig. 5. All these tests were performed at different ages ( 3 days, 7 days, 14 days, 28 days and 90 days). The reported results 
Fig. 3 Workflow diagram for finding amount of fly ash to be added in concrete

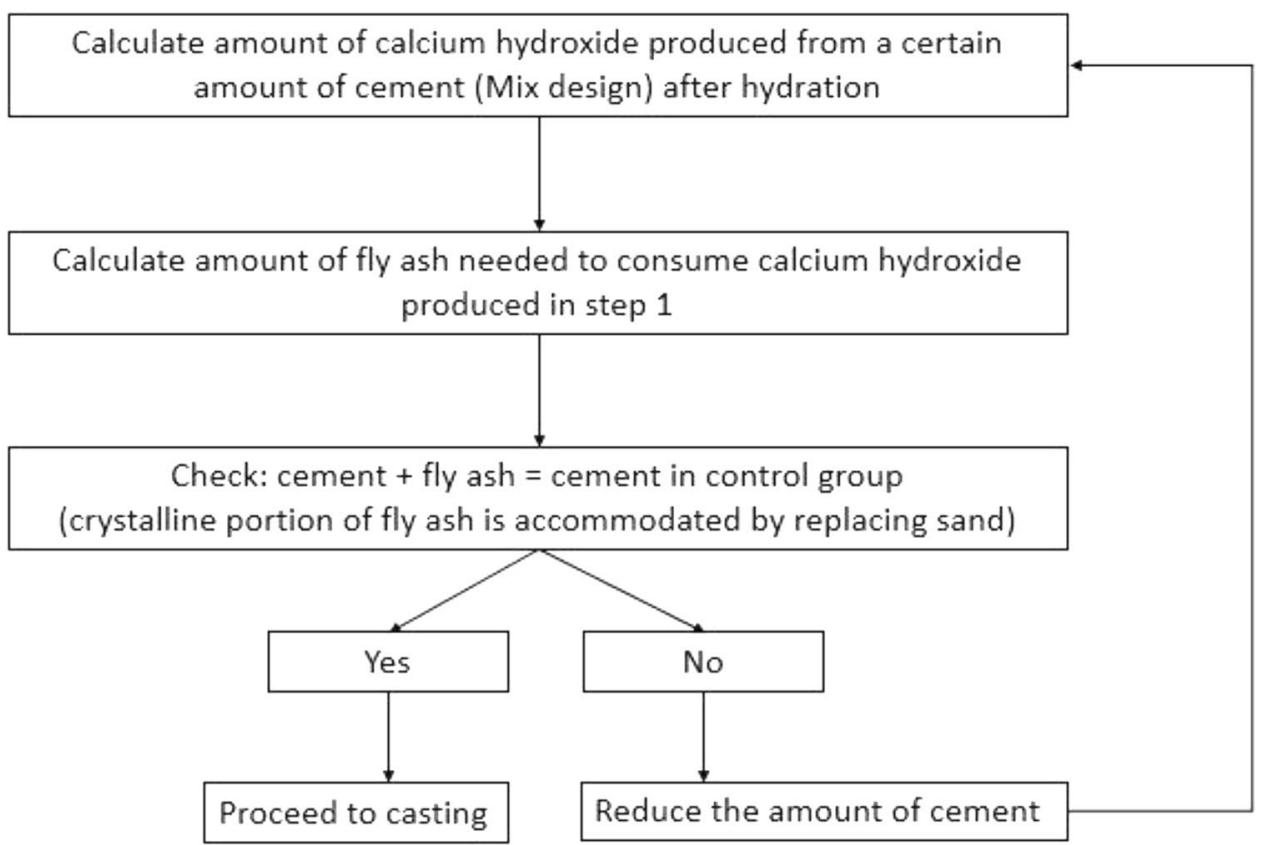

Table 3 Mix design proportions of control group and PRC samples

\begin{tabular}{lllll}
\hline Control group & & & PRC & \\
\cline { 5 - 5 } Ingredient & Amount $\left(\mathrm{Kg} / \mathrm{m}^{3}\right)$ & & Ingredient & Amount $\left(\mathrm{Kg} / \mathrm{m}^{3}\right)$ \\
\hline Cement & 359 & & Cement & 269 \\
Fine aggregate & 897 & & Fine aggregate & 880 \\
Coarse aggregate & 1049 & Coarse aggregate & 1049 \\
Water & 180 & Water & 180 \\
- & - & Fly ash & 90 \\
\hline
\end{tabular}

for each test are the average of three specimens tested at the above-mentioned ages.

\subsection{Compressive and split-tensile strength}

The compressive strength test results and its development with time is shown in Fig. 6. It is clear from experimental tests that control group samples attained compressive strength faster and achieves almost $98 \%$ of its target strength at 28 days. However, PRC samples gained strength at a slower rate for the first 28 days. But, at the age of 90 days, it gained almost $95 \%$ strength as that of control group. The ratio of compressive strength of PRC to control group samples at 28 days and 90 days is 0.68 and 0.95 , respectively.

The split-tensile strength test results are shown in Fig. 7. The split-tensile strength development of both control group and PRC samples follows the same pattern as that of compressive strength. The PRC samples gained strength rapidly after 28 days thereby, attaining almost $96 \%$ strength as that of control group. The percentage increase in compressive strength of control group specimens and
PRC samples between 28 days and 90 days age is $3.52 \%$ and $22 \%$, respectively.

The experimental results clearly illustrate that PRC samples attained strength slowly with time, and at the age of 90 days, gained almost the same strength values. This can be explained from the fact that control group samples complete its hydration process by more than $95 \%$ at 28 days age, leading to the development of calcium hydroxide [30]. The presence of calcium hydroxide ensures a higher $\mathrm{pH}$ environment and activates the reactive species of fly ash [31]. This justifies the rapid strength development and subsequent improvement in other properties of PRC samples after 28 days.

\subsection{Sorption and density}

The sorption test was conducted according to ASTM C1757. This is a very simple and quick test which measures the durability of a concrete sample. The test measures the depth of water intrusion into a concrete sample by subsequent drying and exposing the sample to water and is given by Eq. (1). 
Fig. 4 Lab work a mixing, b fresh plastic concrete after mixing, c casting specimens

Fig. 5 Experiments a splittensile test, $\mathbf{b}$ compressive strength test, c specimens soaked in water for sorption test
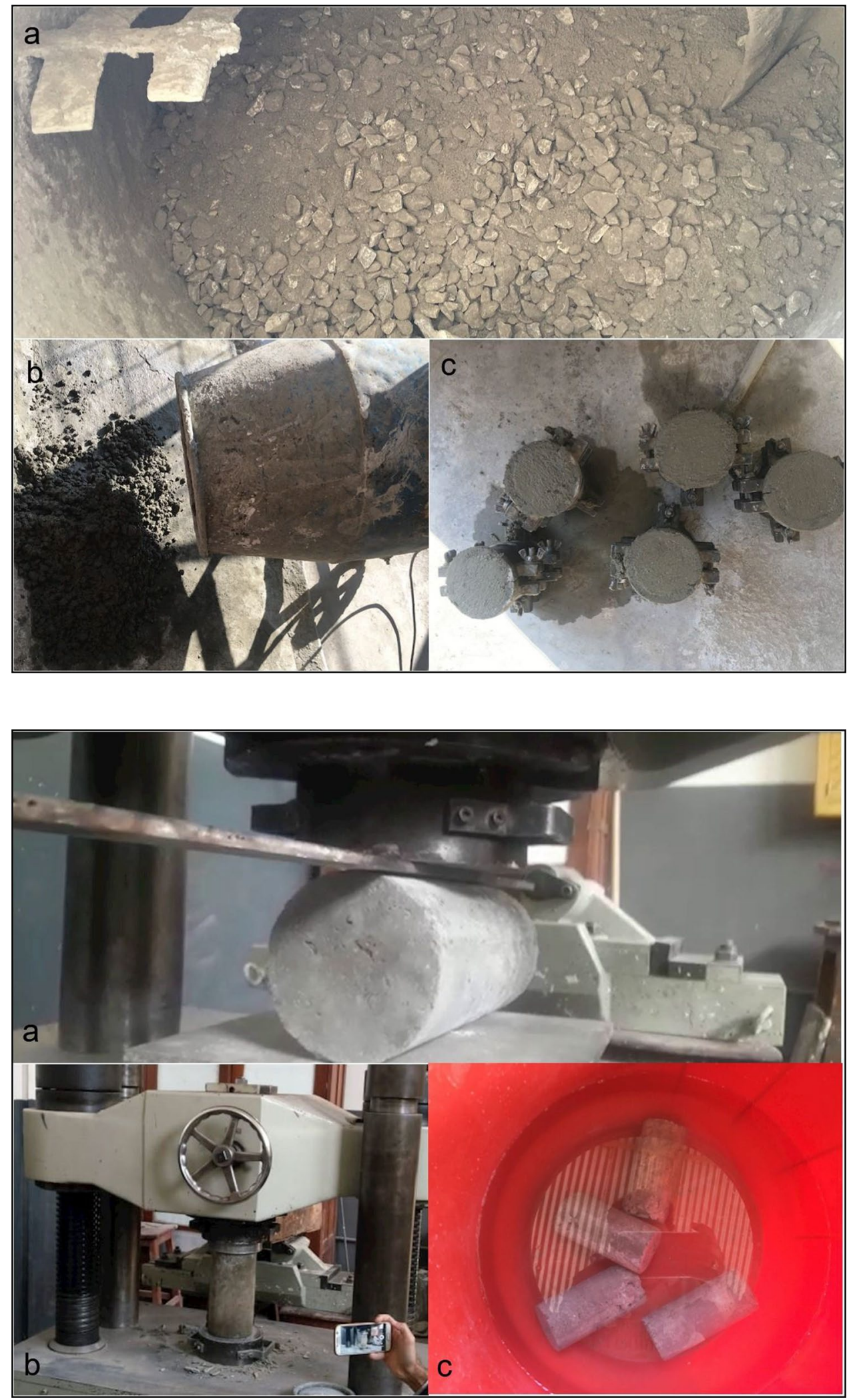


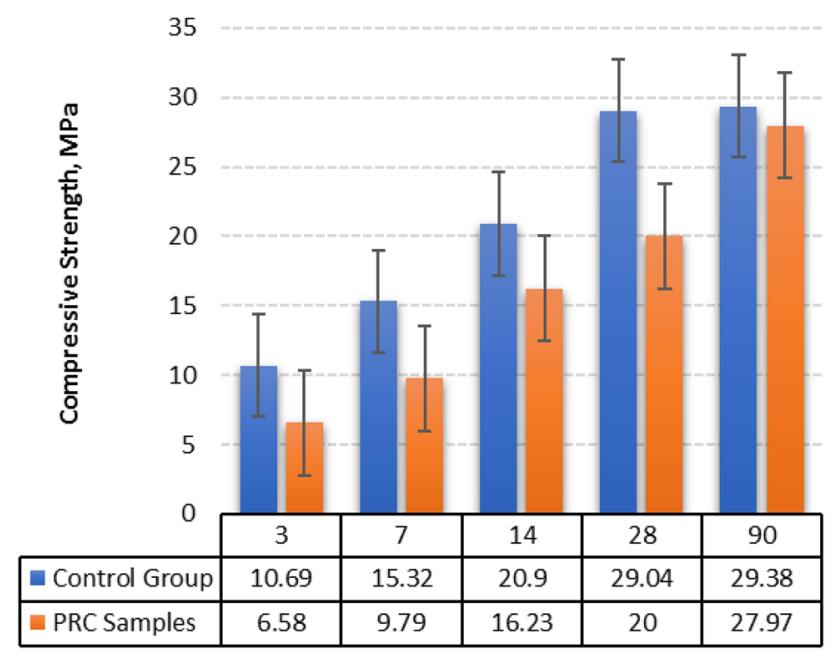

Fig. 6 Compressive strength development with time

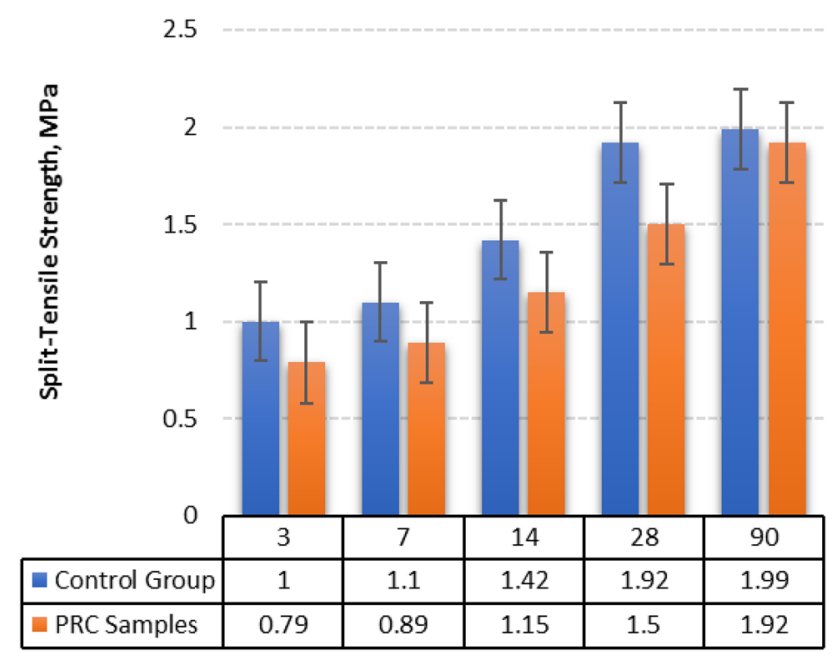

Fig. 7 Split-tensile strength development with time

Sorption $=\frac{W-D}{A^{*} d}$

where $\mathrm{W}=$ mass of sample after immersion in water, $D=$ mass of sample after oven drying, $A=$ area of specimen, $\mathrm{d}=$ density of water.

It is evident from Fig. 8, PRC samples had lower water intrusion values than control group. There is a noticeable decrease in sorption values after 14 days in both samples. Comparing the sorption values at 90 days, the PRC samples had almost $50 \%$ less intrusion than control group. The ratio of sorption values for PRC to control group specimens was 0.75 and 0.48 at 28 days and 90 days age, which shows that PRC samples become less permeable with time. Similar to other tests, the density was also determined at

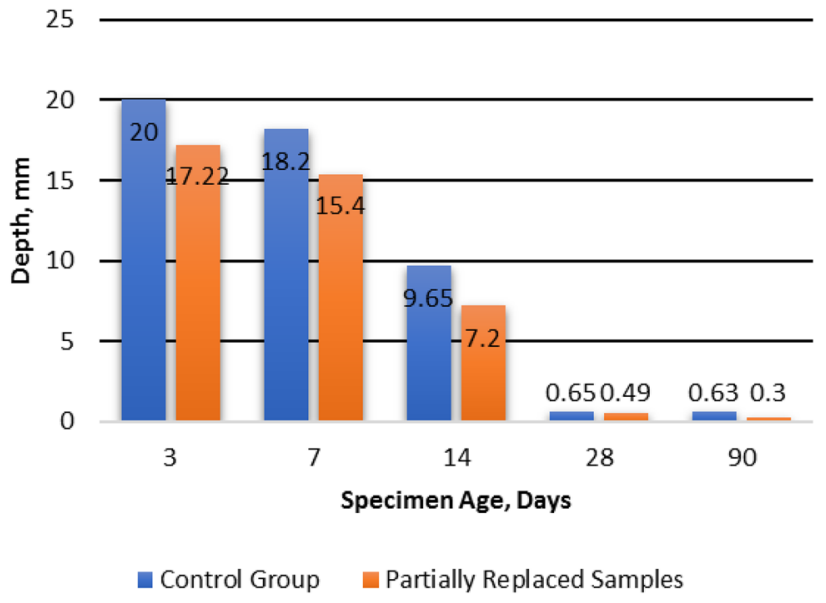

Fig. 8 Sorption test results and its improvement with time

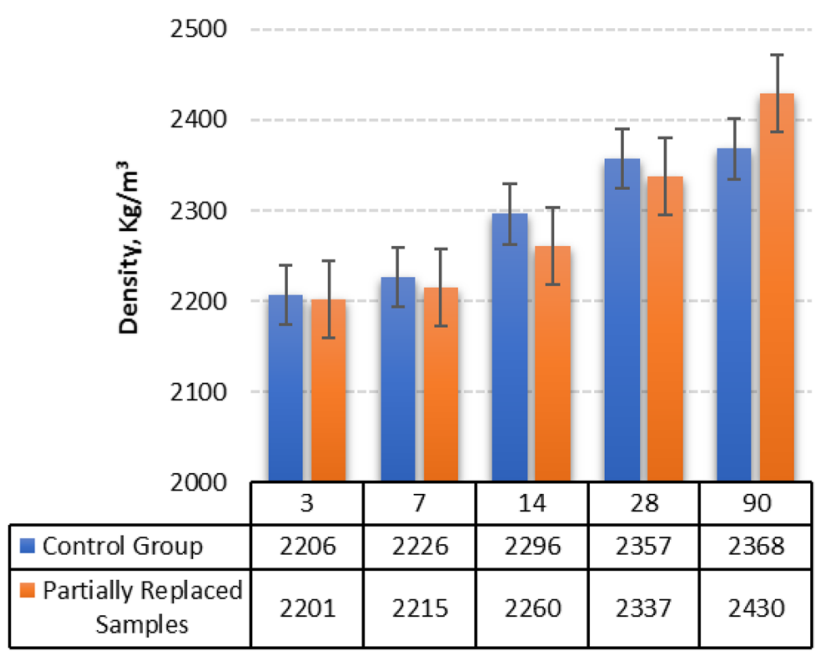

Fig. 9 Density of specimens and its variation with time

different ages. The results show an increasing trend in the density for both types of samples as shown in Fig. 9. The density of control group samples is greater at all ages, except for 90 days, where PRC samples had $2.56 \%$ higher density than control group. The increase in compressive strength with density shows good agreement $\left(R^{2}=0.96\right)$ as shown in Fig. 10.

The experimental results showed improvement in the sorption test values and density of specimens. This is due to the development of binder gel (C-S-H, C-A-H) with time, which made the specimens less permeable. The development of binder gel is also the reason for improvement in compressive strength with time [32]. The increase in density of test samples can be explained from the fact that molecular weight of binder gel is almost 1.8 times more than the calcium hydroxide, which is produced as a result 


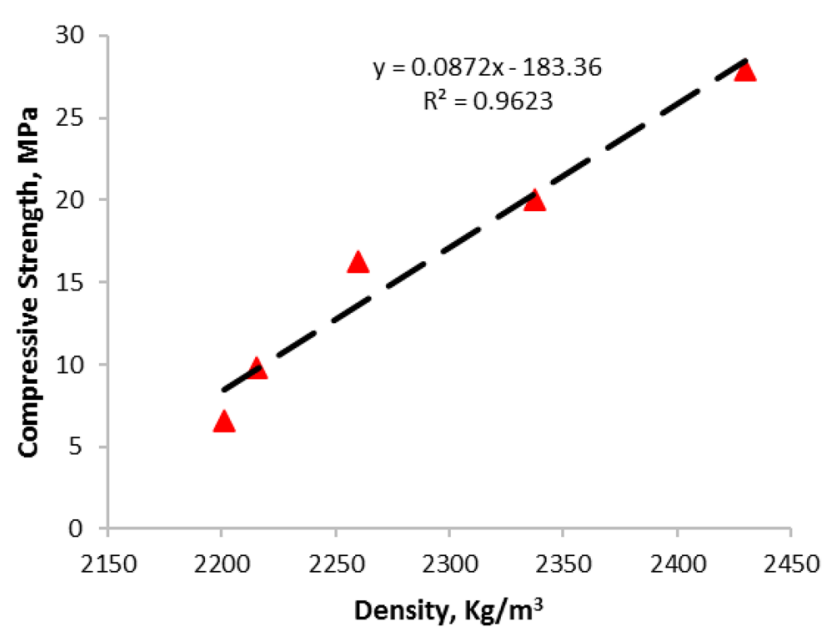

Fig. 10 Relationship between density and compressive strength development with time

of consumption of calcium hydroxide by the reactive species of fly ash [33].

In short, the strength and durability properties of PRC samples are governed by cement hydration present in it for the first 28 days. However, the improvement in strength, density and durability after 28 days, is coming from the contribution of fly ash and calcium hydroxide, thereby, utilizing a waste material for the improving the properties of concrete.

\section{Conclusions}

This study aimed to propose a new approach for finding the optimum amount of fly ash that can be added to concrete. For this purpose, the balanced chemical reactions that occur between cement, water and fly ash were studied. The performance of control group and fly ash samples was compared by performing various tests such as compressive strength, split-tensile strength, sorption and density. The research study concluded the following:

- The chemical composition analysis (XRF) concluded that local fly ash belongs to Class F as per ASTM standards. The quantitative XRD test revealed that about $25 \%$ local fly ash is crystalline, only $75 \%$ of it can act as a pozzolanic material.

- The study also concluded that knowing the chemical composition of cement, elemental composition and amount of crystallinity in fly ash sample; the optimum amount of fly ash that can replace cement can be very easily determined using the proposed methodology without conducting any trials.
- Stoichiometry and quantitative XRD analysis led to the conclusion that about $30 \%$ cement can be replaced with local fly ash for consuming calcium hydroxide produced as a result of cement hydration. The same amount of partial replacement was previously suggested in literature without any obvious reasons/calculations rather, came out as a result of conducting a large number of mix designs \& experimental trials.

- PRC samples showed an increasing trend in compressive \& split-tensile strength with time, as compared to control group (beyond 28 days). PRC samples gained almost $95 \%$ compressive strength as that of control group after 90 days.

- The presence of fly ash also improved the durability of PRC specimens as indicated from the results of sorption test (50\% less penetration as compared to control group). PRC samples had higher density as compared to control group at 90 days age; indicating the consumption of calcium hydroxide (low molecular weight) and formation of binder gel (higher molecular weight), ultimately leading towards reduced permeability and increased strength.

\section{Compliance with ethical standards}

Conflict of interest The authors declare that they have no conflict of interest.

\section{References}

1. Wang J, Qin Q, Hu S, Wu K (2016) A concrete material with waste coal gangue and fly ash used for farmland drainage in high groundwater level areas. J Clean Prod 112:631-638

2. Kox S, Vanroelen G, Van Herck J, De Krem H, Vandoren B (2019) Experimental evaluation of the high-grade properties of recycled concrete aggregates and their application in concrete road pavement construction. Case Stud Constr Mater 11:e00282

3. O'Hegarty R, Kinnane O (2020) Review of precast concrete sandwich panels and their innovations. Constr Build Mater 233

4. Hemalatha T, Ramaswamy A (2017) A review on fly ash characteristics-Towards promoting high volume utilization in developing sustainable concrete. J Clean Prod 147:546-559

5. Chen X, Wan D, Jin L, Qian K, Fu F (2019) Experimental studies and microstructure analysis for ultra high-performance reactive powder concrete. Constr Build Mater 229:116924

6. Antiohos S, Tsimas S (2004) Activation of fly ash cementitious systems in the presence of quicklime: Part I. Compressive strength and pozzolanic reaction rate. Cem Concr Res 34(5):769-779

7. Rashad AM (2015) A brief on high-volume Class F fly ash as cement replacement-A guide for Civil Engineer. Int J Sustain Built Environ 4(2):278-306 
8. Fan Y, Yin S, Wen Z, Zhong J (1999) Activation of fly ash and its effects on cement properties. Cem Concr Res 29(4):467-472

9. Wilińska I, Pacewska B (2018) Influence of selected activating methods on hydration processes of mixtures containing high and very high amount of fly ash: a review. J Therm Anal Calorim 133(1):823-843

10. ACl Committee 232 (2002) "Use of fly ash in concrete". American Concrete Institute

11. Garcia-Lodeiro I, Donatello S, Fernández-Jiménez A, Palomo Á (2016) Hydration of hybrid alkaline cement containing a very large proportion of fly ash: a descriptive model. Materials (Basel) 9(7):605. https://doi.org/10.3390/ma9070605

12. de Matos PR, Foiato M, Prudêncio LR (2019) Ecological, fresh state and long-term mechanical properties of high-volume fly ash high-performance self-compacting concrete. Constr Build Mater 203:282-293

13. Micheal Thomas (2007) "Optimizing the Use of Fly Ash in concrete". Portland Cement Association

14. Atiş CD (2003) High-volume fly ash concrete with high strength and low drying shrinkage. J Mater Civ Eng 15(2):153-156

15. Nath $P$, Sarker $P$ (2011) Effect of fly ash on the durability properties of high strength concrete. Procedia Eng 14:1149-1156

16. Ammasi AK, Ragul (2018) Strength and durability of high volume fly ash in engineered cementitious composites. In: Materials today: proceedings, 2018, vol 5, no. 11, pp 24050-24058

17. LudwikGolewski G (2019) Estimation of the optimum content of fly ash in concrete composite based on the analysis of fracture toughness tests using various measuring systems. Constr Build Mater 213:142-155

18. Ludwik Golewski G (2019) Measurement of fracture mechanics parameters of concrete containing fly ash thanks to use of Digital Image Correlation (DIC) method. Measurement 96-105

19. Grzegorz Ludwik Golewski TS (2016) A study of Mode III fracture toughness in young and mature concrete with fly ash additive. Solid State Phenom 254

20. ACl Committee 211.1 (2002) Standard practice for selecting proportions for normal, heavyweight, and mass concrete

21. ASTM C127-15 Standard Test Method for Relative Density (Specific Gravity) and Absorption of Coarse Aggregate (2015) ASTM Int I:5
22. ASTM C128-15 (2015) ASTM C128 - Standard Test Method for Relative Density (Specific Gravity) and Absorption of Fine Aggregate. ASTM Int

23. ASTM C136/C136M - 19 Standard Test Method for Sieve Analysis of Fine and Coarse Aggregates," ASTM Int (2019)

24. ASTM C618 - 2019 Standard Specification for Coal Fly Ash and Raw or Calcined Natural Pozzolan for Use (2019)

25. Neville AM (1963) Properties of concrete, 5th ed. Prentice Hall

26. Samouh H, Rozière $E$, Wisniewski V, Loukili A (2017) Consequences of longer sealed curing on drying shrinkage, cracking and carbonation of concrete. Cem Concr Res 95:117-131

27. ASTM C39 - 2015 Standard Test Method for Compressive Strength of Cylindrical Concrete Specimens (2015) ASTM Stand, pp 1-7

28. ASTM C - 496 Standard Test Method for Splitting Tensile Strength (2014) Annu. B. ASTM Stand, vol I, pp 1-5

29. ASTM Standard C1757 - Standard Test Method for Determination of One-Point, Bulk Water Sorption of Dried Concrete (2014) ASTM Int., vol I, pp 14-16

30. Rahman F, Raheel M, Khan R (2019) Fuzzy logic model for investigating the effect of steel fibers on mechanical properties of concrete. SN Appl Sci 1:1205. https://doi.org/10.1007/s4245 2-019-1226-5

31. Kang SH, Jeong Y, Kim MO, Moon J (2019) Pozzolanic reaction on alkali-activated Class $\mathrm{F}$ fly ash for ambient condition curable structural materials. Constr Build Mater 218:235-244

32. Das S, Ray S, Sarkar S (2020) Early strength development in concrete using preformed CSH nano crystals. Constr Build Mater 233:117214

33. Şahin R, Demirboğa R, Uysal H, Gül R (2003) The effects of different cement dosages, slumps and pumice aggregate ratios on the compressive strength and densities of concrete. Cem Concr Res 33(8):1245-1249

Publisher's Note Springer Nature remains neutral with regard to jurisdictional claims in published maps and institutional affiliations. 